Article

\title{
Lignosulfonate-Based Polyurethane Adhesives
}

\author{
Sandra Magina ${ }^{1}\left(\mathbb{D}\right.$, Nuno Gama $^{1}$, Luísa Carvalho ${ }^{2,3} \mathbb{D}^{\mathbb{D}}$, Ana Barros-Timmons ${ }^{1} \mathbb{D}$ \\ and Dmitry Victorovitch Evtuguin $1, *$ (D)
}

1 CICECO_Aveiro Institute of Materials and Department of Chemistry, University of Aveiro, 3810-193 Aveiro, Portugal; smagina@ua.pt (S.M.); nuno.gama@ua.pt (N.G.); anabarros@ua.pt (A.B.-T.)

2 LEPABE-Laboratory for Process, Environmental and Energy Engineering, Faculty of Engineering, University of Porto, 4200-465 Porto, Portugal; lhcarvalho@estv.ipv.pt

3 DEMad-Department of Wood Engineering, Polytechnic Institute of Viseu, 3504-510 Viseu, Portugal

* Correspondence: dmitrye@ua.pt

Citation: Magina, S.; Gama, N.; Carvalho, L.; Barros-Timmons, A.; Evtuguin, D.V. Lignosulfonate-Based Polyurethane Adhesives. Materials 2021, 14, 7072. https://doi.org/ $10.3390 /$ ma14227072

Academic Editor: Andrea Bernasconi

Received: 29 October 2021

Accepted: 18 November 2021

Published: 21 November 2021

Publisher's Note: MDPI stays neutral with regard to jurisdictional claims in published maps and institutional affiliations.

Copyright: (c) 2021 by the authors. Licensee MDPI, Basel, Switzerland. This article is an open access article distributed under the terms and conditions of the Creative Commons Attribution (CC BY) license (https:/ / creativecommons.org/licenses/by/ $4.0 /)$.

\begin{abstract}
The feasibility of using lignosulfonate (LS) from acid sulphite pulping of eucalyptus wood as an unmodified polyol in the formulation of polyurethane (PU) adhesives was evaluated. Purified LS was dissolved in water to simulate its concentration in sulphite spent liquor and then reacted with 4,4'-diphenylmethane diisocyanate (pMDI) in the presence or absence of poly(ethylene glycol) with $M_{\mathrm{W}} 200\left(\mathrm{PEG}_{200}\right)$ as soft crosslinking segment. The ensuing LS-based PU adhesives were characterized by infrared spectroscopy and thermal analysis techniques. The adhesion strength of new adhesives was assessed using Automated Bonding Evaluation System (ABES) employing wood strips as a testing material. The results showed that the addition of $\mathrm{PEG}_{200}$ contributed positively both to the homogenization of the reaction mixture and better crosslinking of the polymeric network, as well as to the interface interactions and adhesive strength. The latter was comparable to the adhesive strength recorded for a commercial white glue with shear stress values of almost $3 \mathrm{MPa}$. The optimized LS-based PU adhesive formulation was examined for the curing kinetics following the Kissinger and the Ozawa methods by non-isothermal differential scanning calorimetry, which revealed the curing activation energy of about $70 \mathrm{~kJ} \cdot \mathrm{mol}^{-1}$.
\end{abstract}

Keywords: lignosulphonate; adhesive; pMDI; polyurethane; adhesion; curing kinetics; PEG; DSC; ABES

\section{Introduction}

Wood-based composites cover a variety of products, from fiberboards to laminated beams, and are used for numerous non-structural and structural applications such as panels for interiors, furniture, support structures in buildings, etc. Wood raw-materials used in the production of wood-based composites include fibers, particles, flakes, veneers, laminates, or lumber [1,2]. In most conventional wood-based composites, adhesive bonding is achieved by non-renewable petroleum-derived thermosetting synthetic resins including phenolformaldehyde (PF), urea-formaldehyde (UF), melamine-formaldehyde (MF), polyurethanes (PUs) and polymeric diphenylmethane diisocyanate (pMDI). Several auxiliary chemicals are also added to plasticize adhesive polymers, enhance tackiness, improve heat resistance, or lower costs $[1,3,4]$. Due to the waning of petrochemical supplies but also due to the public awareness related to the environment and its protection, as well as governmental regulations, the use of bio-based adhesives in wood and fiber composites has attracted scientific and economic interest for the last several decades [4-7].

Within the diverse synthetic resins aforementioned, PUs are versatile designer polymers that display varied properties being adjustable to a wide range of applications namely foams (rigid and flexible), elastomers, paints and coatings, adhesives, and even for medical applications [8-11]. The global PU market size was valued at USD 70.67 billion in 2020 and is expected to grow at a compound annual growth rate (CAGR) of $3.8 \%$ from 2021 to 2028 [12]. Typically, PUs are prepared through the addition of isocyanates (comprising 
more than one reactive isocyanate group per molecule) and polyols (containing two or more reactive $\mathrm{OH}$ groups per molecule) yielding polyurethane linkages in the polymer backbone [8-11]. While isocyanates are very harmful and, at the end of their life cycle, PUs may release toxic compounds such as amines leading to health and environmental concerns, so far it has been very difficult to replace them. Furthermore, the implementation of regulations by some governments have motivated both academia and industry to develop safer and "greener" alternative routes to produce more environmentally friendly PUs. To reduce the environmental impact of PUs, efforts have focused on the replacement of fossil derived polyols by bio-based ones, such as castor oil [13-19] and other vegetable oils [20-22], crude glycerol [15,23], lignin [15,24,25], among others.

Technical lignins can act as macropolyols in PU synthesis due to high amount of phenolic and aliphatic hydroxyl moieties in their structure [24-30]. The direct exploitation of technical lignins, as polyols or blending with industrial polyols, is energetically and environmentally advantageous [31] and the ensuing biomass-based PUs are more biodegradable than those derived from petroleum-based polyols [32]. Hence, lignins can be used as such, or after chemical modification to obtain a more reactive lignin, alone or in combination with other polyols [24,27-30,33-35]. It is well known that lignins (in general) act both as a network former (due to its functionality being higher than 2) and as a reinforcing component in PU formulations. The latter is mainly due to the high content of condensed aromatic rings in lignin contributing to its generally stiff structure. Therefore, to counterbalance the stiff character of the lignin macromolecules, other polyols can be used as soft segments, such as poly(ethylene glycol) (PEG) and poly(propylene glycol) (PPG) [16,29,36,37], or bio-based polyols, such as castor oil [15-19], crude glycerol [15] and poly(E-caprolactone) (PCL) [38] yielding grafted or cross-linked PUs with the possibility of controlling their flexibility and/or rigidity. Due to the high content of reactive aliphatic $\mathrm{OH}$ in lignins, for instance in organosolv lignins, these can be used as macromonomers without further chemical modification [34,35]. However, considering that the structure of technical lignins is extremely dependent on the plant source from which it is obtained, the final properties of the lignin-based PUs depend highly on the lignin's plant source [39]. The low reactivity of the lignin macromonomer toward isocyanates is usually related to the fact that only a certain proportion of the total $\mathrm{OH}$ groups can react (due to steric hindrance from the highly branched three-dimensional structure of lignin and intramolecular hydrogen bonding) yielding products without desirable performance [39-41]. From several studies in the literature around $20 \mathrm{wt} . \%$ of unmodified lignin is the limit for lignin incorporation in PU formulations [28].

Another important issue for the adhesive industry is the control of the curing process since it affects the final properties of the material. This requires knowledge of the kinetics of the curing process. In a previous work, Gama and co-workers [13] studied the curing process of castor oil-based PU adhesives by differential scanning calorimetry (DSC) using the two most known approaches, the Kissinger [42] and the Ozawa [43] methods. Both methods are rapid, easy to use and depend on a series of experiments based on heating samples at several different heating rate [44]. Kinetic parameters, such as the activation energy $\left(E_{\mathrm{a}}\right)$ of the cure and the degree of cure (or conversion, $\alpha$ ), were determined from nonisothermal measurements using different heating rates $(\beta)$. $\alpha$ varies from 0 to 1 , i.e., from completely uncured to fully cured, and can be determined by Equation (1).

$$
\alpha=H_{(t)} / H_{T}
$$

where $H_{(t)}$ is the enthalpy of the reaction up to time $t$ and $H_{T}$ is the total enthalpy of the reaction. Additionally, the rate of cure $\left(d \alpha \cdot d t^{-1}\right)$ is proportional to the rate of the heat generated and can be determined by Equation (2).

$$
d \alpha / d t=1 / H_{T} \times d H_{(t)} / d t
$$


when the curing rate $(\beta)$ is increased, the peak temperature $\left(T_{p}\right)$ shifts to a higher temperature range, and this can be used to calculate $E_{a}$, using methods such as the Kissinger method or Ozawa method [44], according to Equations (3) and (4), respectively.

$$
\begin{gathered}
\ln \left(\beta / T_{p}^{2}\right)=C-E_{a} /\left(R T_{p}\right) \\
\ln (\beta)=C-E_{a} /\left(R T_{p}\right)
\end{gathered}
$$

where $C$ is a constant derived from $E_{\mathrm{a}}$, the kinetic constant $\left(k_{0}\right)$ and the universal gas constant $(R)$. By plotting $\ln \left(\beta / T_{\mathrm{p}}{ }^{2}\right)$ vs. $1 / T_{\mathrm{p}}$ and $\ln (\beta)$ vs. $1 / T_{\mathrm{p}}$, the value of $E_{\mathrm{a}}$ can be determined.

The ultimate goal of this work is to use industrial sulphite spent liquor (SSL) as a bio-based polyol to substitute petroleum-based polyols in the formulation of bio-based PU adhesives and also to reduce costs associated with LS purification. SSL from acid sulphite pulping of hardwoods, such as eucalypt, is mainly composed of LS, xylo-oligosaccharides and contains high amounts of pentose sugars, extractives of polyphenolic origin and inorganic salts [45-47]. To avoid the eventual participation of other components from SSL in the PU synthesis, LS was purified by dialysis and contained minimal organic/inorganic impurities. Therefore, in the adhesive preparation unmodified purified eucalyptus LS was used as bio-based polyol, water as LS solvent, PEG $_{200}$ as a soft segment co-polyol and pMDI as a basic crosslinker. Since lignins generally contribute to PU stiffness, the addition of PEG with $M_{\mathrm{W}} 200$ ( $\mathrm{PEG}_{200}$ ) allows tuning the viscoelastic properties of PUs. Therefore, the variation in $\mathrm{PEG}_{200}$ content was studied and the final adhesion properties of the resulting adhesives were evaluated. Structural and thermal characterization was performed on the most relevant adhesive formulations. Finally, the kinetic parameters of the curing process were assessed for the most promising adhesive formulations.

\section{Materials and Methods}

\subsection{Materials and Reagents}

Lignosulfonates (LS) were purified by dialysis in water for $24 \mathrm{~h}$ from thick spent liquor of the industrial magnesium-based acidic sulphite pulping of Eucalyptus globulus wood, which was supplied by Caima Company (Caima-Indústria de Celulose S. A., Constância, Portugal). The detailed purification and characterization of purified LS procedures were previously reported elsewhere and showed that it contained $17.1 \mathrm{wt} . \%$ of $\mathrm{HSO}_{3}$ groups, $2.4 \mathrm{wt} . \%$ of phenolic and $5.5 \mathrm{wt} . \%$ aliphatic $\mathrm{OH}$ groups [48]. Dibutyltin dilaurate (DBTDL) was purchased from Sigma-Aldrich Chem. Comp. (Madrid, Spain). PEG with average $M_{\mathrm{w}} 200$ ( $\mathrm{PEG}_{200}$ ) was supplied by Acros Organics (Lisbon, Portugal). Oligomeric isocyanate 4, $4^{\prime}$-methylene diphenyl diisocyanate (pMDI) (Voranate M229) with $31.1 \%$ of NCO, a functionality of 2.7 , a viscosity of $190 \mathrm{mPa} \cdot \mathrm{s}\left(\right.$ at $25^{\circ} \mathrm{C}$ ) and an isocyanate equivalent of 135 (values provided by the supplier) was kindly supplied by Dow Chemicals (Estarreja, Portugal). Commercial poly(vinyl acetate) (PVA) glue (white glue) was purchased in the local market. The structures of the main components of the synthesized PU formulations are depicted in Figure 1.

\subsection{LS-Based Adhesive Synthesis}

For all formulations, purified LS powder (500 mg) was first dissolved in water $(400 \mu \mathrm{L})$ or a mixture of water with $\mathrm{PEG}_{200}(0,50,100$ and $150 \mu \mathrm{L})$ to form the base solution, in a glass vessel with screw cap with a magnetic stirring bar, at room temperature. The volume of water used was initially optimized to ensure full solubilization of LS and ease of stirring. The mixture was kept under constant magnetic stirring for $5 \mathrm{~min}$ and then $50 \mu \mathrm{L}$ of DBTDL was added as the catalyst. Finally, 900 or $1000 \mathrm{mg}$ of crosslinker pMDI was introduced in the reaction mixture and the reaction proceeded for a certain time period ranging from $30 \mathrm{~s}$ to 5 min depending on the application. For all formulations, the quantities of LS, water and DBTDL were kept constant (500 mg, $400 \mu \mathrm{L}$ and $50 \mu \mathrm{L}$, respectively) while only the contents of $\mathrm{PEG}_{200}$ and pMDI were varied, according to the formulations presented in 
Table 1. The molar ratio NCO/OH was calculated based on the contribution of the total amount of $\mathrm{OH}$ groups in LS [48] and $\mathrm{OH}$ groups in $\mathrm{PEG}_{200}$.<smiles>CCOC(CO)C(c1cc(OC)c(O)c(OC)c1)C(CO)CO</smiles>

eucalypt LS<smiles>CCO[CH]C(C)(CO)CO</smiles><smiles>Cc1cc(CCc2ccc([N+](=O)[O-])cc2)ccc1N=O</smiles>

Figure 1. Conventional structural representation of eucalypt LS showing phenolic and aliphatic $\mathrm{OH}$ groups, $\mathrm{PEG}_{200}$ and commercial polymeric isocyanate $\mathrm{pMDI}$.

Table 1. Formulations of the LS-based PU adhesives prepared.

\begin{tabular}{ccccccc}
\hline Formulation & LS (mg) & $\mathbf{H}_{\mathbf{2}} \mathbf{O}(\boldsymbol{\mu L})$ & $\mathbf{P E G}_{\mathbf{2 0 0}}(\boldsymbol{\mu L})$ & DBTDL $(\mu \mathrm{L})$ & MDI (mg) & $\begin{array}{c}\text { NCO/OH } \\
\text { Molar Ratio * }\end{array}$ \\
\hline 1 & 500 & 400 & 0 & 50 & 900 & $3.2: 1$ \\
2 & 500 & 400 & 50 & 50 & 900 & $2.6: 1$ \\
3 & 500 & 400 & 100 & 50 & 900 & $2.2: 1$ \\
4 & 500 & 400 & 150 & 50 & 900 & $1.9: 1$ \\
5 & 500 & 400 & 0 & 50 & 1000 & $3.6: 1$ \\
6 & 500 & 400 & 100 & 50 & 1000 & $2.9: 1$ \\
7 & 500 & 400 & 150 & 50 & 1000 & $2.4: 1$ \\
8 & 500 & 400 & & & &
\end{tabular}

For the study of the curing process using DSC and DMA, the stirring time was $30 \mathrm{~s}$. For the preparation of the samples used for FTIR and TGA analyses, a 5 min stirring was performed after which the adhesive was left curing for $48 \mathrm{~h}$ at room temperature. The same procedure was followed for samples submitted to the ABES testing.

\subsection{Adhesive Characterization}

LS-based PU adhesives were characterized by Fourier transform infrared spectroscopy (FTIR) using a FTIR System Spectrum BX (PerkinElmer, Waltham, MA, USA), coupled with a universal ATR sampling accessory, in absorbance from 4000 to $500 \mathrm{~cm}^{-1}$ with a $4 \mathrm{~cm}^{-1}$ resolution. Adhesive samples were analyzed as such after complete curing ( $48 \mathrm{~h}$ at room temperature), 128 scans were averaged, and all spectra were baseline corrected and normalized (by the min-max normalization technique [49]) for further analysis.

Thermogravimetric analysis (TGA) of the samples was carried out using a Setsys Evolution 1750 TGA-DSC thermogravimetric analyzer (Setaram, Caluire, France) equipped with a DSC plate rod accessory. Samples were analyzed from room temperature to $800{ }^{\circ} \mathrm{C}$ at a heating rate of $10{ }^{\circ} \mathrm{C} \cdot \mathrm{min}^{-1}$ under nitrogen flow rate of $200 \mathrm{~mL} \cdot \mathrm{min}^{-1}$ using an alumina crucible.

Dynamic mechanical analysis (DMA) of the polymer films was carried out using a Tritec 2000 DMA instrument (Triton Technology, Leicestershire, UK). The LS-based PU formulation before curing was studied as such using a stainless-steel material pocket accessory [50] in single cantilever bending mode. A first temperature scan for the LSbased formulation curing process was carried out from room temperature up to $180{ }^{\circ} \mathrm{C}$ at a heating rate of $5{ }^{\circ} \mathrm{C} \cdot \mathrm{min}^{-1}$, with a displacement of $0.020 \mathrm{~mm}$ and at a frequency of 
deformation (oscillating frequency) of $1 \mathrm{~Hz}$. Next, the same material pocket containing the cured LS-based PU was used to perform a second temperature scan in order to determine its $T_{\mathrm{g}}$. This second DMA run was carried out from $-20^{\circ} \mathrm{C}$ up to $200{ }^{\circ} \mathrm{C}$ (before degradation) at a heating rate of $2{ }^{\circ} \mathrm{C} \cdot \mathrm{min}^{-1}$, with a displacement of $0.020 \mathrm{~mm}$ and at a frequency of $1 \mathrm{~Hz}$.

Differential scanning calorimetry (DSC) analysis was carried out on a Power Compensation Diamond DSC (PerkinElmer, Waltham, MA, USA) previously calibrated using the melting points of indium and lead as standards for temperature calibration and the heat of fusion of indium as standard for heat calibration [51,52]. The LS-based PU formulation samples (around 5-10 $\mathrm{mg}$ ) were encapsulated in hermetically sealed stainless-steel pans that can withstand a maximum internal pressure of 24 bar. Dynamic (non-isothermal) DSC runs were performed in the temperature range from -10 to $150{ }^{\circ} \mathrm{C}$, at different heating rates, namely $5,10,15$ and $20^{\circ} \mathrm{C} \cdot \mathrm{min}^{-1}$.

The strength development of LS-based adhesives was assessed using the automated bonding evaluation system (ABES, Corvallis, OR, USA) at the Department of Wood Engineering, Polytechnic Institute of Viseu. Tests with ABES apparatus were carried out using beech (Fagus sylvatica) veneer strips (with a dimension of $117 \mathrm{~mm} \times 20 \mathrm{~mm}$ and thickness of $0.5 \mathrm{~mm}$ ). For each test, a new LS-based adhesive sample formulation was prepared. After adding pMDI (according to the synthesis method), the formulation was mixed using a magnetic stir for $5 \mathrm{~min}$. Afterwards, $10 \mathrm{mg}$ of pre-cured adhesive was applied and evenly distributed on the standard configuration of the beech veneer (over $5 \mathrm{~mm}$ of the edge of the beech veneer strips to cover the bonding area of $100 \mathrm{~mm}^{2}$ ), according to Figure 2. Then, a wood strip without adhesive was overlapped over the one with adhesive making sure the two strips were aligned giving an overlapping area of $100 \mathrm{~mm}^{2}(20 \mathrm{~mm} \times 5 \mathrm{~mm})$. This strip was glued to another strip in the same configuration and a $500 \mathrm{~g}$ load (49 $\mathrm{kPa}$ ) was placed on top of the jointed wood strips. The structure was kept in this form for $24 \mathrm{~h}$ at room temperature for adhesive curing and the strips to be glued. For each formulation, a minimum of at least three sets of bonded strips were prepared.

(a)

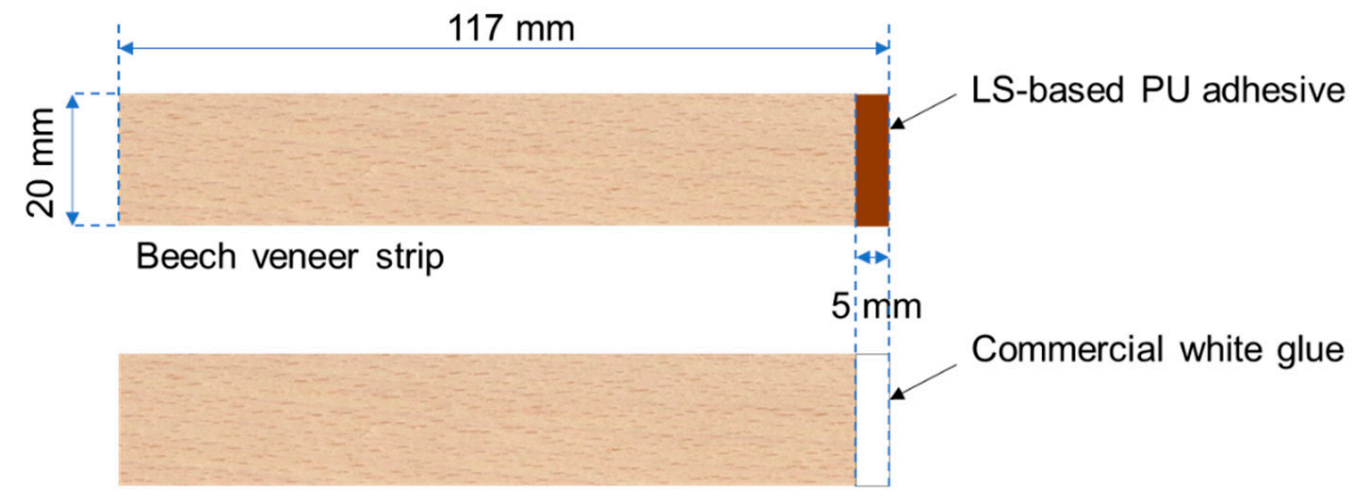

(b)

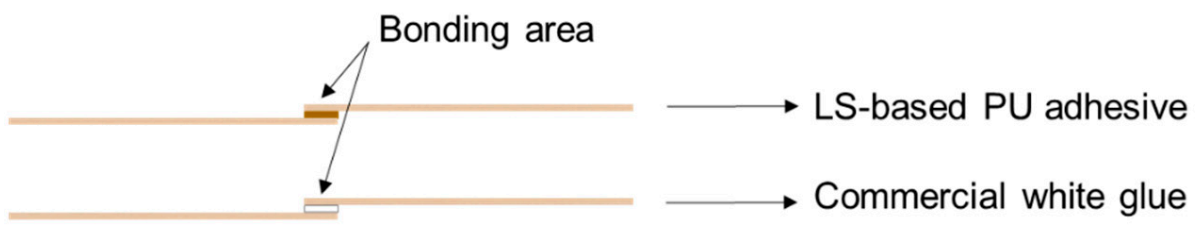

Figure 2. Schematic representation of assembly for the adhesive test: (a) the beech veneer strips with applied adhesive and (b) the final set of two bonded beech veneer strips. 


\section{Results and Discussion}

The polycondensation of unmodified lignins with isocyanates with large molecular structures such as pMDI is unlikely to occur without the addition of catalysts due to the lack of reactivity, which is related to the steric hinderance of $\mathrm{OH}$ groups in lignin and of NCO groups in pMDI as well as low diffusion due to the high viscosity of the reaction medium [34]. Accordingly, DBDTL was used as a catalyst. It is assumed that in LS, as in other technical lignins, the primary $\mathrm{OH}$ groups are the most reactive with isocyanate moieties [34]. This assumption is reflected in the reaction scheme proposed in Figure 3, where the most reactive $\mathrm{OH}$ groups in the $\gamma$ position of the lignin structural unit react with pMDI. It is noteworthy that steric hindrance of phenolic $\mathrm{OH}$ groups is much more pronounced in hardwood than in softwood lignin, because the former has quite a high ratio of syringyl (S) over guaiacyl (G) structural units [53,54]. In fact, the eucalyptus LS used in this work had the particularly high S:G ratio of 78:22 [48]. Furthermore, in the presence of water, the reactivity of pMDI with lignin is hampered by isocyanate competition reactions with the formation of the corresponding amines $[6,10,14]$. Therefore, it can be expected that a polymeric network of low crosslinking will result from the reaction of pMDI and LS alone. However, the addition of highly reactive water-soluble polyol to the reaction system can increase crosslinking between polymer chains and, if a polyol is polar enough to improve segmental movement of the resulting network, it can positively contribute to the adhesive properties of the final synthetic glue. Based on these considerations, a series of formulations were synthesized (Table 1) using, in addition to pMDI and LS, low molecular weight polyethylene glycol diol $\left(\mathrm{M}_{\mathrm{w}} 200\right)$. The produced LS-based adhesives were structurally and thermally characterized and the adhesion strength have been evaluated.

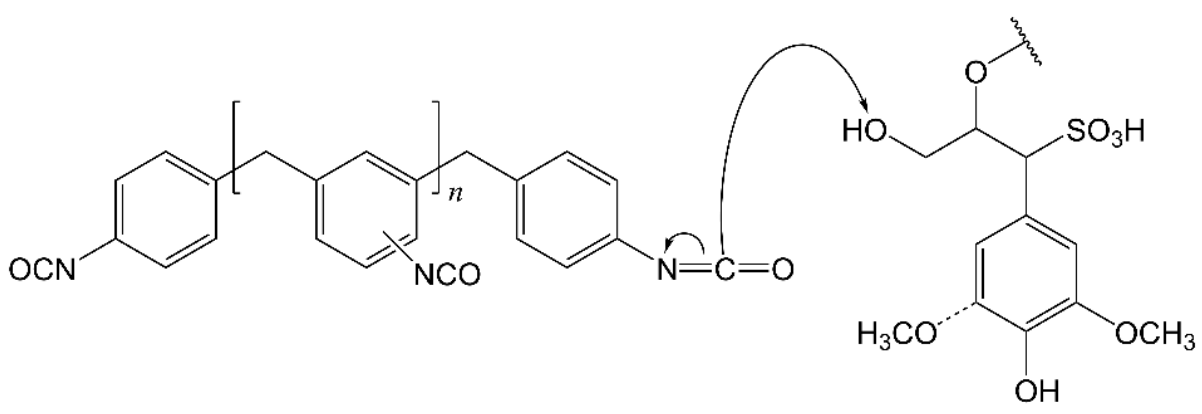

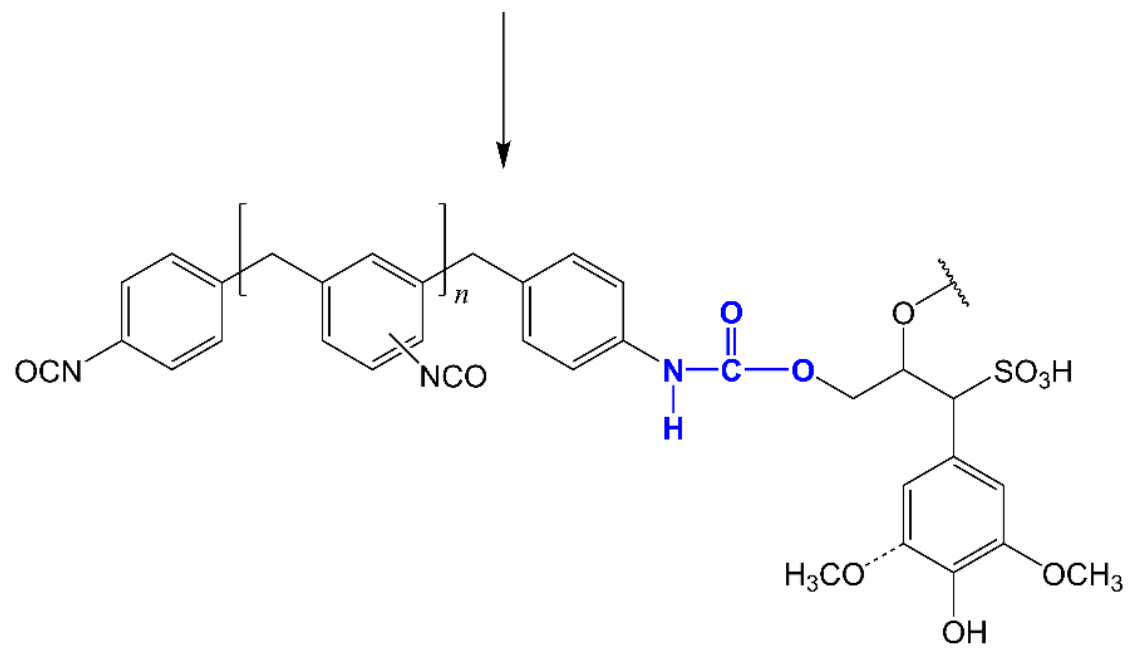

Figure 3. Schematic representation of the reaction between NCO group in PMDI and aliphatic $\mathrm{OH}$ in the $\gamma$-position of eucalypt LS. 


\subsection{Chemical and Thermal Characterization of LS-Based PU Adhesives}

The parent LS and typical adhesive formulations involving LS and pMDI (LS-MDI) and LS, pMDI and PEG $_{200}$ were structurally characterized by FTIR-ATR. Although semiquantitative, this technique allows for rough conclusions. The corresponding normalized spectra of LS, LS-based adhesive without (LS-MDI) and with PEG $_{200}$ (LS-MDI-PEG) are presented in Figure 4 and the bands assignment are listed in Table 2. The reaction of $\mathrm{OH}$ groups in LS with pMDI in the PU samples produced was confirmed by the decrease in the intensity of the band peaked at $3430 \mathrm{~cm}^{-1}(\delta \mathrm{O}-\mathrm{H})$ and the band at $1036 \mathrm{~cm}^{-1}$ $(\delta \mathrm{C}-\mathrm{OH})[45,55,56]$. Simultaneously, the newly formed bands in the PU samples were observed at 1766 (very slight), 1504 (the most evident), 1406 (also significant) and $1216 \mathrm{~cm}^{-1}$, and assigned to the stretching vibration in urethane groups [57]. Noteworthy that the band at $1504 \mathrm{~cm}^{-1}$ in PU is the result of superposition of lignin aromatic band and the secondary NH band, which shoulder is clearly observed at ca. $1530 \mathrm{~cm}^{-1}$. Meanwhile, the characteristic bands at 2262 (C-N stretching), $1644\left(\mathrm{C}=\mathrm{O}\right.$ stretching) and $1590 \mathrm{~cm}^{-1}(\mathrm{~N}-\mathrm{H}$ deformations) [57] are assigned to unreacted isocyanate groups from pMDI still present in the PU product suggesting that the PU curing process was not complete. This is in agreement with the formulation's composition (Table 1) as NCO groups were used in excess amount. It is noteworthy that the integral intensity of the isocyanate band at $2262 \mathrm{~cm}^{-1}$ was less to ca. 30\% for LS-MDI-PEG than for LS-MDI (Figure 4), thus confirming the importance of adding $\mathrm{PEG}_{200}$ to obtain more extensive crosslinking of the molecular network.

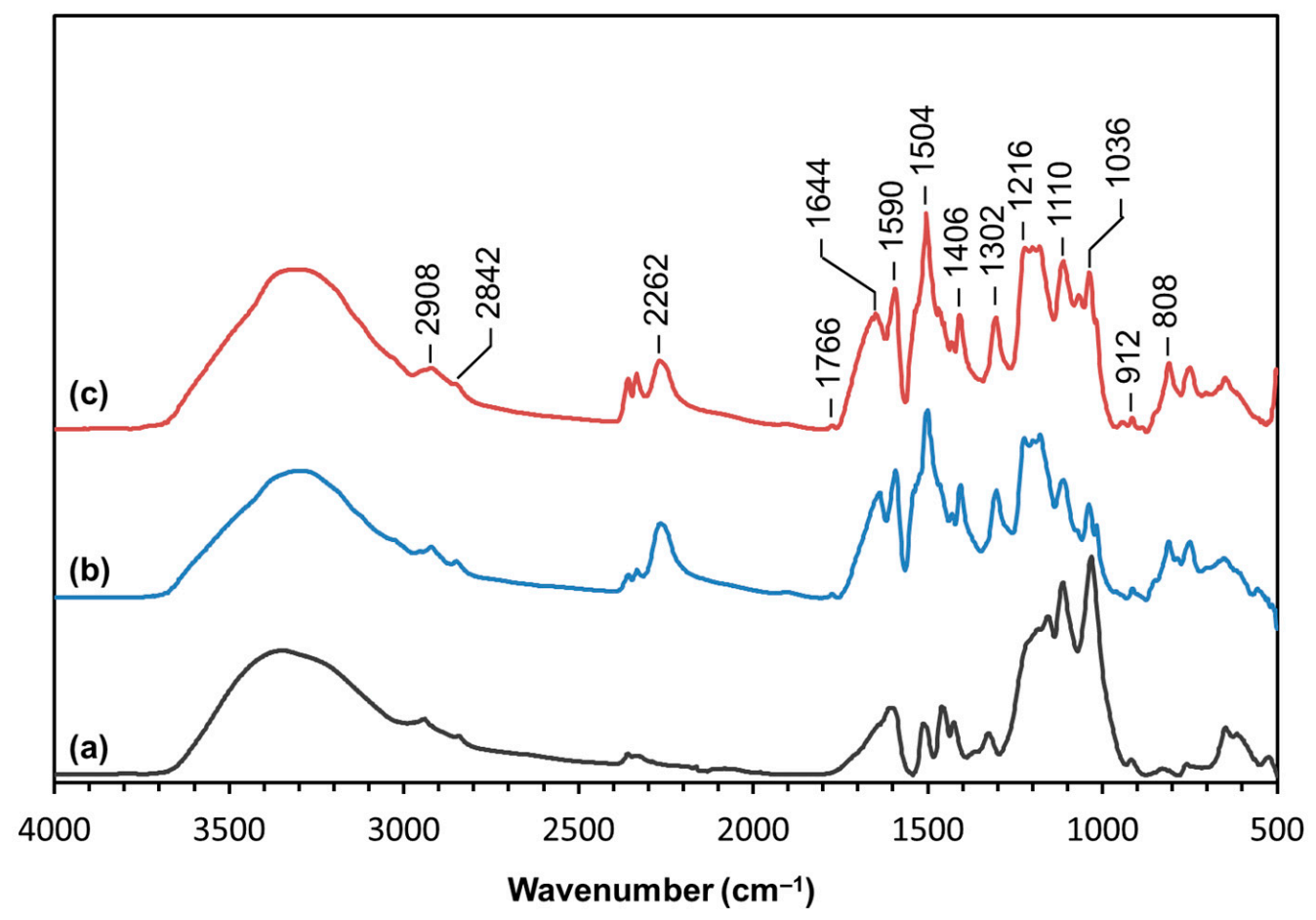

Figure 4. Normalized FTIR-ATR spectra of (a) LS, (b) LS-based PU adhesive (formulation 5 in Table 1), and (c) LS-based PU adhesive with PEG 200 (formulation 8 in Table 1). 
Table 2. Assignments of the FTIR bands in the spectra of LS, LS-MDI and LS-MDI-PEG [45,55-58].

\begin{tabular}{cc}
\hline Band $\left(\mathbf{c m}^{-\mathbf{1})}\right.$ & Assignment \\
\hline $3600-3200$ & $\mathrm{O}-\mathrm{H}$ stretching; $\mathrm{N}-\mathrm{H}$ stretching (urethane group) \\
$2908 / 2842$ & $\mathrm{C}-\mathrm{H}$ stretching in $-\mathrm{CH}_{2}-,-\mathrm{CH}_{3}$ and $\mathrm{O}-\mathrm{CH}_{3}$ groups \\
2262 & $\mathrm{C}-\mathrm{N}$ stretching (isocyanate group) \\
1766 & $\mathrm{C}=\mathrm{O}$ stretching (urethane group) \\
1644 & $\mathrm{C}=\mathrm{O}$ stretching (isocyanate group) \\
1590 & $\mathrm{~N}-\mathrm{H}$ deformation (isocyanate group), lignin aromatic group \\
1504 & $\mathrm{~N}-\mathrm{H}$ bending (urethane group), lignin aromatic group \\
1406 & $\mathrm{C}-\mathrm{N}$ stretching in amide (urethane group) \\
1302 & $\mathrm{C}-\mathrm{N}$ stretching (urethane group) \\
1216 & $\mathrm{C}-\mathrm{N}$ stretching (urethane group) \\
1036 & $\mathrm{C}-\mathrm{O}$ stretching in aliphatic OH \\
808 & $\mathrm{C}-\mathrm{H}$ deformation out-of-plane, aromatic ring \\
\hline
\end{tabular}

The thermal behavior of LS, LS-PU (formulation 5 in Table 1) and LS-PU-PEG (formulation 8 in Table 1) are different from each other (Figure 5a). Under inert atmosphere $\left(\mathrm{N}_{2}\right.$ flow), LS undergoes a first weight loss with a maximum loss at around $120^{\circ} \mathrm{C}$ (Figure $5 \mathrm{~b}$ ), related to the release of moisture followed by the degradation of functional groups (around $330{ }^{\circ} \mathrm{C}$, Figure $5 \mathrm{~b}$ ), such as sulphonic groups, and the release of low molecular mass products $[59,60]$ giving rise to a quite high char content (41\%). LS- PU and LS-PEG-PU also undergo a first weight loss around $60-100{ }^{\circ} \mathrm{C}$ (Figure 5b) related mostly to the release of moisture.

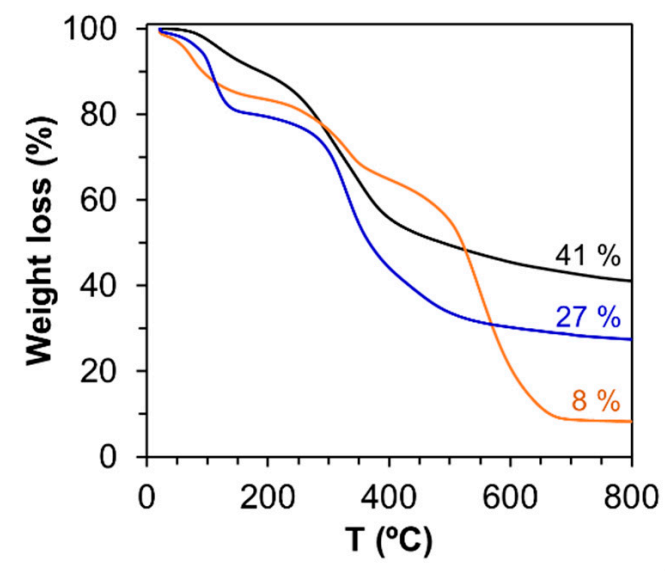

(a)

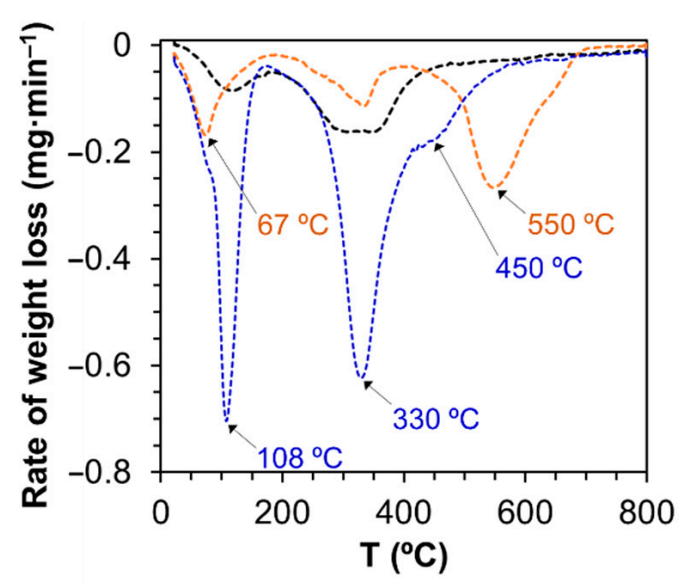

(b)

Figure 5. TGA curves of LS (- - ), LS-based PU without PEG $_{200}$ (formulation 5; - - LS-PU), and LS-based PU containing PEG 200 (formulation 8; - - LS-PEG-PU): (a) weight loss under inert $\mathrm{N}_{2}$ gas flow and (b) derivative of the weight loss.

The degradation of PUs can usually be divided into two major stages. The first stage is dominated by the degradation of the hard segments, while the second stage is controlled by the soft segments (polyol) [13,61]. Yet, all thermograms present a weight loss at lower temperatures attributed to the loss of water. This was expected since the adhesives were prepared in aqueous media. Regarding LS-PU, the first stage with a maximum weight loss at $335{ }^{\circ} \mathrm{C}$ is most likely related to the decomposition of urethane moieties in the PU and other functional groups from LS, the second slow weight loss stage with a maximum weight loss at $550{ }^{\circ} \mathrm{C}$ was attributed to further structural rearrangements of pMDI and LS counterparts during char formation [25]. Regarding LS-PEG-PU, the weight loss registered below $100{ }^{\circ} \mathrm{C}$ even higher than for LS-PU in agreement with the fact that water interacts strongly with PEG so it was not efficiently removed during the cure. In what concerns the degradation of the polymeric material, the first stage with a maximum weight loss 
at $330{ }^{\circ} \mathrm{C}$ is related to the decomposition of urethane groups and LS (similarly to LS-PU) but, in this case, the second stage is more intense and a shoulder appears around $450{ }^{\circ} \mathrm{C}$ in Figure 5b. Curiously, no mass loss is detected at higher temperature like for LS-PU. These differences are most probably associated with the presence of PEG [61]. Under inert gas, $\mathrm{PEG}_{200}$ displays a single stage decomposition with a maximum weight loss at $290{ }^{\circ} \mathrm{C}$ (Figure S1, Supplementary Materials). Hence, the decomposition of $\mathrm{PEG}_{200}$ contributed to the increased intensity of the degradation peak at ca. $330^{\circ} \mathrm{C}$. Furthermore, considering the presence of the shoulder at $450^{\circ} \mathrm{C}$ and the absence of degradation at higher temperature, as well as the higher amount of char formed, it is clear that the presence of $\mathrm{PEG}_{200}$ in LS-PEG-PU results in a very distinct degradation pathway. Significantly higher residual char content in the thermal degradation of LS-PEG-PU than LS-PU (Figure 5) is indicative of the much denser molecular structure of the former. This is in tune with FTIR analysis results that showed the eventual intensification of molecular crosslinking in LS-pMDI adhesive with addition of $\mathrm{PEG}_{200}$ to the reaction system.

The curing of LS-based PU formulation with and without the addition of $\mathrm{PEG}_{200}$ was studied by DMA analysis under non-isothermal conditions, as depicted in Figure $6 a(1), b(1)$. A post-curing heating scan was carried out to determine the $T_{\mathrm{g}}$ of both LS-based PU adhesives (Figure $6 \mathrm{a}(2), \mathrm{b}(2)$ ). For each PU formulation, a duplicate was prepared and analyzed. It should be noted that the curves of the storage and loss modulus, $E^{\prime}$ and $E^{\prime \prime}$ respectively, are not shown due to the influence of the material pocket.

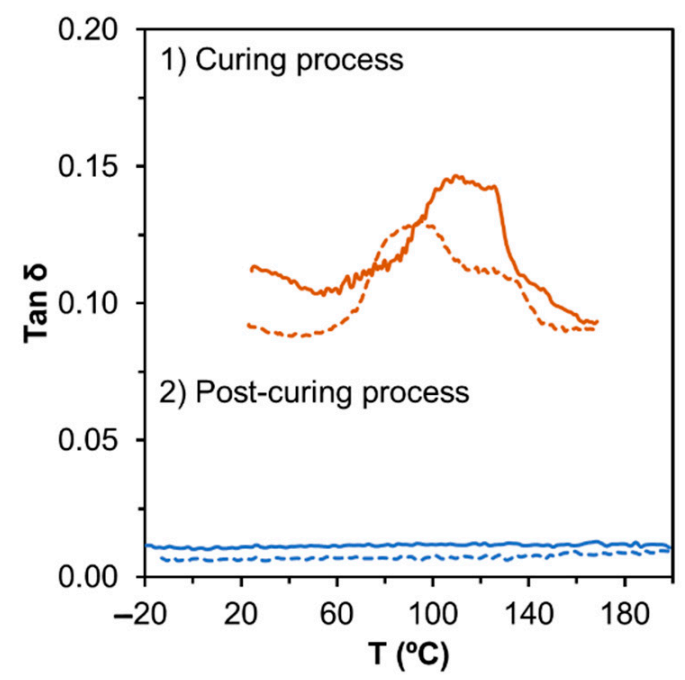

(a)

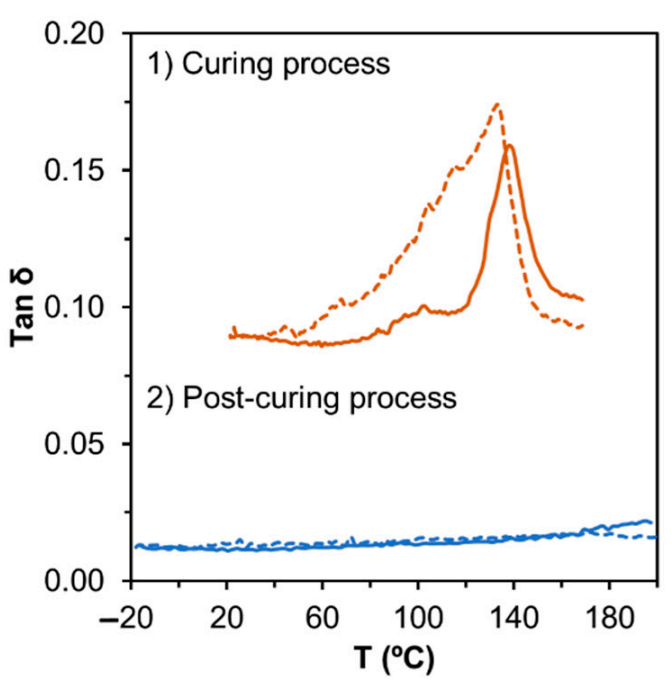

(b)

Figure 6. DMA profiles of (a) LS-based PU without PEG 200 (LS-PU) and (b) LS-based PU with PEG 200 (LS-PEG-PU). Full line and dashed lines are duplicates of the same formulation.

Concerning the curing process, in the $\tan \delta$ profile the transition assigned to the PU curing starts around $60^{\circ} \mathrm{C}$ for both types of LS-based PU formulations with and without $\mathrm{PEG}_{200}$, i.e., formulations 5 and 8 (Table 1), respectively. To study curing processes using DMA analysis, two points should be determined, the point of gelation (when the material changes from a viscous liquid to a viscoelastic solid, which is the $E^{\prime}-E^{\prime \prime}$ crossover or where $\tan \delta$ is equal to one) and the point of vitrification (when the curing system reaches such high viscosity that limits further curing and the bulk reaction stops, commonly taken as the onset plateau of the storage modulus) [62]. However, in this case, this type of study could not be carried out since the $E^{\prime}$ and $E^{\prime \prime}$ curves could not be considered due to the use of the material pocket accessory. Still, some observations can be pointed out when comparing the DMA profile of each formulation with its respective duplicate. Taking into account that each formulation was replicated using exactly the same procedure, it is clear that the curing behavior of two equal PU formulations does not match (the profile has some similarities 
but is still different). The only possible explanation for this occurrence is the mixing process after the addition of crosslinker pMDI and consequently the reagents diffusion. In the formulation without $\mathrm{PEG}_{200}$, isocyanate groups react with water and $\mathrm{OH}$ groups in LS (most likely aliphatic $\mathrm{OH}$ groups in the $\gamma$-position [34]), while in the formulation with $\mathrm{PEG}_{200}$, isocyanate groups react with water, $\mathrm{OH}$ groups in $\mathrm{LS}$ and $\mathrm{OH}$ groups from $\mathrm{PEG}_{200}$. Reactions between the isocyanate groups with available $\mathrm{OH}$ groups depend mostly on the accessibility/reactivity of different $\mathrm{OH}$ groups and also on the efficiency of the mixing process and consequently diffusion. Therefore, due to the high apparent viscosity of the reaction mixture, it is possible that the mixing was not perfect enough and that the extent of crosslinking was different for the same formulation affecting the curing process. In fact, the addition of $\mathrm{PEG}_{200}$ to the formulation also changed the curing profile (Figure $6 \mathrm{~b}(1)$ ) compared to the one observed for the LS-based PU without $\mathrm{PEG}_{200}$. In this case, the temperature at which the curing process appears to be completed increased to around $135-140^{\circ} \mathrm{C}$ probably due to a chain entanglement effect and subsequent diffusion limitation of reactive moieties $[63,64]$. Moreover, the broadening of $\tan \delta$ peak for the system containing $\mathrm{PEG}_{200}$ seems to be less pronounced indicating a more uniform crosslinked network.

Since DMA is much more sensitive to detect $T_{\mathrm{g}}$ than other techniques, such as DSC, and can easily measure transitions that may not be apparent in other thermal methods [62], after the curing process, each material pocket containing the cured PU adhesive was cooled back to $-20^{\circ} \mathrm{C}$ and was used to perform a second DMA run to determine the $T_{\mathrm{g}}$. Based on TGA analysis (Figure 5), this run was carried out only up to $200{ }^{\circ} \mathrm{C}$ to avoid potential thermal degradation of the products. Surprisingly, no $T_{\mathrm{g}}$ was observed in any post-curing tan $\delta$ profile, which means that LS-based PU adhesives do not display clear softening behavior in the temperature range between -20 and $200^{\circ} \mathrm{C}$. The values of $T_{\mathrm{g}}$ are dependent on the lignin and PEG contents and usually increase with increasing weight fraction of lignin (stiff component) and decrease with increasing weight fraction of PEG (soft segment) [34,65]. Though most values reported in the literature (ranging from -40 to $\left.105^{\circ} \mathrm{C}[34,65]\right)$ were determined by DSC and values determined from DMA analysis can be higher than DSC's by $25^{\circ} \mathrm{C}$ [62], some softening behavior would be expected.

\subsection{Evaluation of the Adhesion Strength of LS-Based PU Adhesives}

It is known that an efficient wood adhesive must spread across the wood surface but also wet the said surface to increase the contact area, i.e., the interface. Hence, the goal is to develop molecular interactions between the adhesive and wood. Therefore, a good adhesive wetting can produce effective wood bonding. Yet, other parameters are also important such as efficient solidification of the adhesive to provide strength (in this case, through chemical curing) and sufficient deformability (related to the flexibility of the resulting adhesive due to the addition of $\mathrm{PEG}_{200}$ ) of the cured adhesive to reduce stress [66]. ABES testing was performed to evaluate the strength of adhesion of the LSbased PU adhesives and to assess the effect of the $\mathrm{PEG}_{200}$ amount on the adhesion results. Additionally, results were compared with those obtained using a commercial white glue (Figure 7). ABES testing measures the force in tensile mode needed to break the adhesive bond and shear strength gives an indication of the strength of an adhesive. Therefore, the higher is the force needed to break the bond, the higher is the shear strength value. At first glance, all LS-based PU adhesives showed adhesion strengths somewhat lower or similar to those obtained using commercial white glue. This means that LS-based PUs displayed variable adhesive properties depending on the formulation composition, but still comparable to the commercial adhesive. Another fact is that the errors associated with each strength value are quite high. This was especially noticeable for the commercial white glue. Considering that one duplicate of each formulation was prepared, the results suggest that there are significant differences between duplicates of the same formulation, as observed when performing DMA analysis, affecting crosslinking and thus the curing process and eventually the adhesion strength. Furthermore, for each formulation, a minimum of three sets of bonded strips were prepared and even within the same formulation, different 
strength values were obtained (yet, only concordant values were chosen and individual data are not shown). This indicates that for the same formulation, the samples applied on the wood strip are different from one another, possibly due to poor reagents mixing. Furthermore, only $10 \mathrm{mg}$ of adhesive was applied to the strip, which may not be fully representative of the entire product. It could be also suggested that comparing formulations containing $900 \mathrm{mg}$ of pMDI with those containing $1000 \mathrm{mg}$ of pMDI, strength values are quite similar. However, it appears that the strength values of formulations containing $1000 \mathrm{mg}$ showed less variability than those of formulations containing $900 \mathrm{mg}$ of pMDI. These results suggest that when the system comprise higher amounts of pMDI it is under kinetic control (higher reactivity, hence more reticulation) as opposed to diffusion control (which leads to higher heterogeneity, hence less reticulation) when lower amounts of pMDI are used. As expected, the best adhesion results were obtained with the addition of $100 \mu \mathrm{L}$ of $\mathrm{PEG}_{200}$ as this polyol provides flexibility and promotes further crosslinking extension as discussed above.

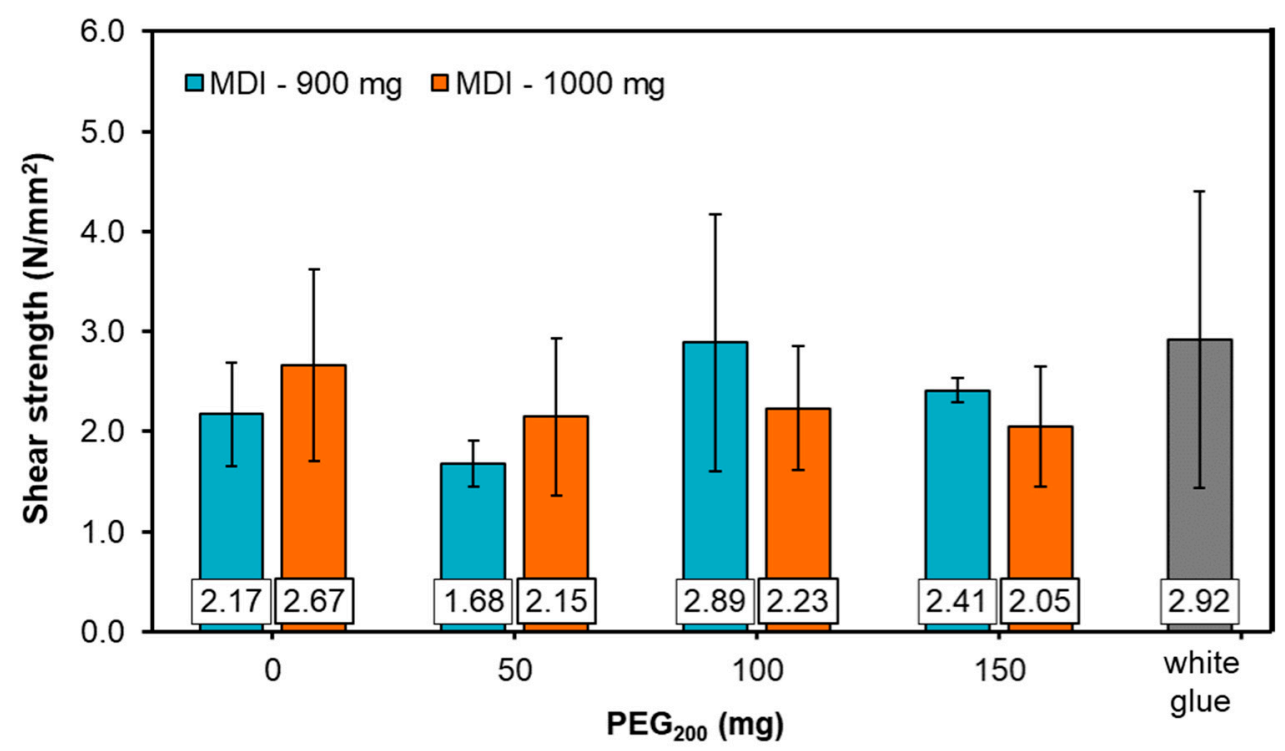

Figure 7. Shear strength values for each LS-based PU formulation as a function of the content of $\mathrm{PEG}_{200}$ against the shear strength of commercial white glue (each value corresponds to the average of a minimum of three values).

Indeed, in practice, when adhesives were prepared, formulations containing higher amount of pMDI and also containing PEG $_{200}$ were easier to homogenize. Overall, adhesion strength results showed some effect of the variation in pMDI content and the amount of added $\mathrm{PEG}_{200}$. In particular, with a lower content of $\mathrm{pMDI}$ in the reaction mixture, the shear stress showed a maximum with the addition of $\mathrm{PEG}_{200}(100-150 \mathrm{mg}$, Figure 7). This is not particularly surprising since, as suggested by Thring and co-workers [67], the chain length of $\mathrm{PEG}_{200}$ may be too short to bridge in the network due to steric hindrance from the chemical structure of lignin. Therefore, a balance must be found between the lignin content and $\mathrm{PEG}_{200}$ since lignin-derived $\mathrm{PU}$ materials produced using $\mathrm{PEG}_{200}$ are either too weak at low lignin content, or too brittle at higher amounts of lignin. In this case, it is possible that PEG with higher molecular weight could have provided a different adhesion behavior.

It is noteworthy that when performing ABES testing, the way adhesive bonding breaks is extremely important. Figure 8 depicts some photographs of the bonding areas of some wood strips after ABES testing. Since the main objective of ABES testing is to determine the adhesive strength, the adhesive failure must occur within the adhesive (as is shown by green circles when adhesive remained in both strips), but not adhesive failure with adhesion to the substrate (as is shown by yellow circles when the adhesive was transferred to one of the strips due to adhesion failure between adhesive and substrate). Additionally, substrate failure (red circles) should not occur neither though, when it does, it 
means that the strength of the adhesive is too high [68]. Based on the results obtained, the occurrence of adhesion failure to the substrate suggests that the LS-based PU adhesive did not sufficiently wet the strip surface. Adhesives must flow to the surface of the wood and penetrate the entire tissue of the wood so that intermolecular interactions (strong covalent bonds and/or mechanical locking) between the adhesive and the wood can occur [66]. In fact, all adhesives lacked sufficient fluidity and low viscosity to be sufficiently absorbed by the wood strip. In addition, the bonding failure of the adhesives was very irregular confirming the lack of homogeneity in the composition of each LS-based PU formulation. In practice, optimization of the adhesive composition in relation to the bonded substrate is still required.

\section{Formulation 4}

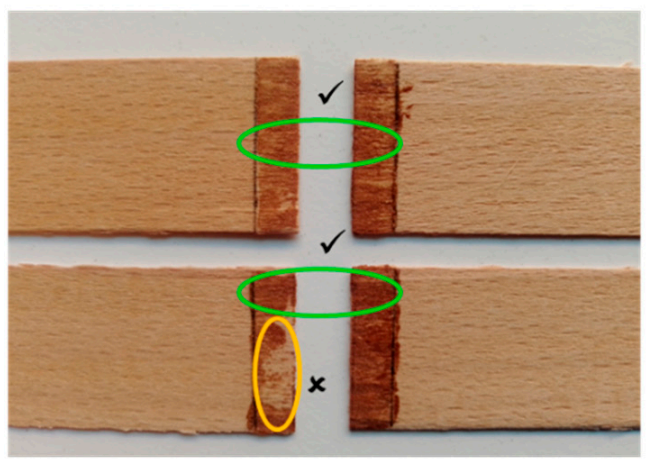

\section{Formulation 5}

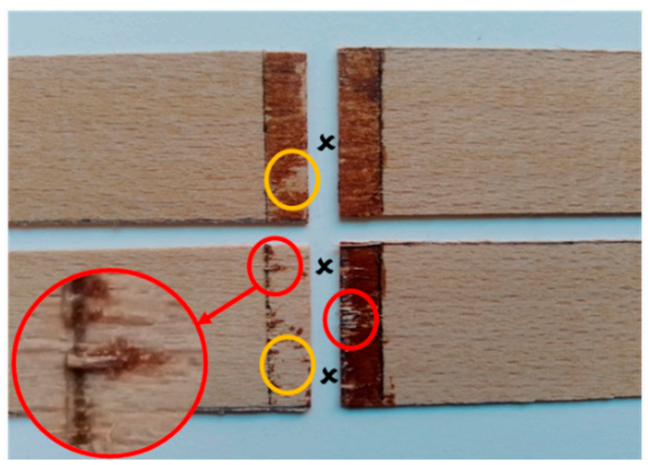

Formulation 8

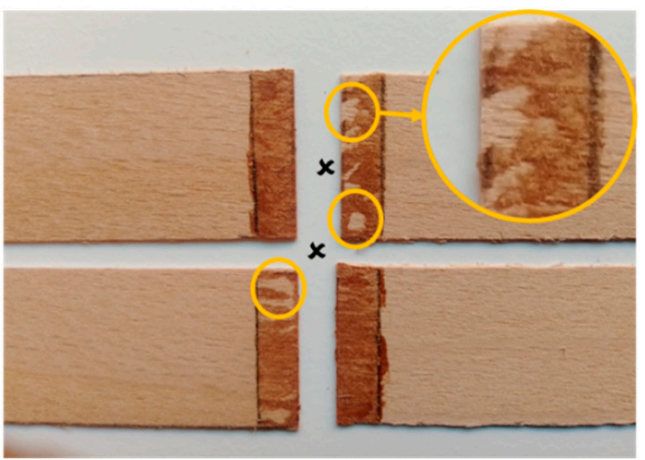

commercial glue

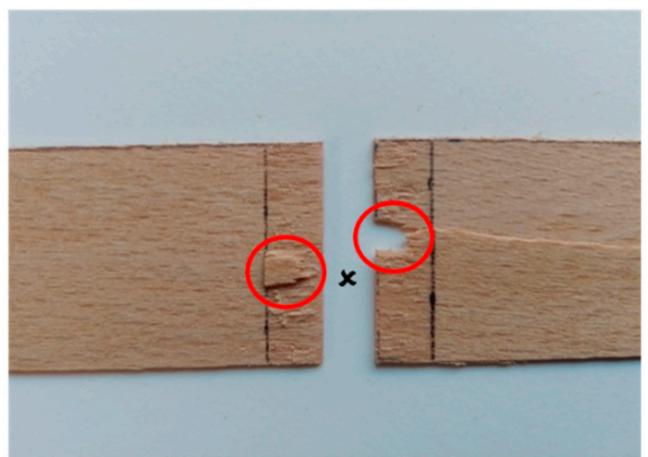

Figure 8. Photographs of selected beech veneer strips after ABES testing showing different types of failure ( $O$ Adhesion failure within the adhesive-good result $\checkmark$; 0 Adhesion failure to the substrate-failed result $\mathbf{x}$; and $\mathbf{O}$ substrate failure-failed result $\mathbf{x}$ ).

According to our observations, the addition of $\mathrm{PEG}_{200}$ favored better adhesion of the adhesive to the substrate (wood strips). These adhesive formulations (e.g., formulations $3,4,7$, and 7) revealed also the highest values of shear stress (Figure 7). Apparently, the improved crosslinking during curing of the PU adhesive with the proper proportion of LS, pMDI and PEG $_{200}$ (e.g., formulation 3, Table 1) contributed positively to the adhesive strength in bulk.

\subsection{Kinetic Study of the Curing Process of LS-based PU Adhesive Containing PEG 200}

The study of the curing process is highly important in the industry as it is a complementary analysis tool that provides additional understanding on the mechanism of the curing reaction, in order to control and optimize the curing process. Therefore, the cure of LS-PEG ${ }_{200}(150)-\mathrm{PU}$ (formulation 8), which is the most promising and flexible, was studied using non-isothermal DSC. The plots of the degree of cure (conversion, $\alpha)$ and the rate of heat generated $(\mathrm{d} \alpha / \mathrm{dT})$ at different heating rates $(\beta)$ as a function of the temperature $(T)$ are depicted in Figure 9. As expected [13,69], the conversion rate increased 
up to a maximum value and then decreased indicating that the free volume between the macromolecules allows molecular movement during the curing process up to 70 to $80 \%$ of conversion but beyond crosslinks start to break down. Furthermore, peaks shifted toward higher temperatures as $\beta$ increased. As the temperature increased, $\alpha$ also increased up to 1 (maximum degree of conversion) slowly at the initial curing stage and then more abruptly at the end. The S-shaped curves confirmed that the reaction only starts after a certain temperature is achieved and this occurrence is in agreement with the literature $[13,70]$.

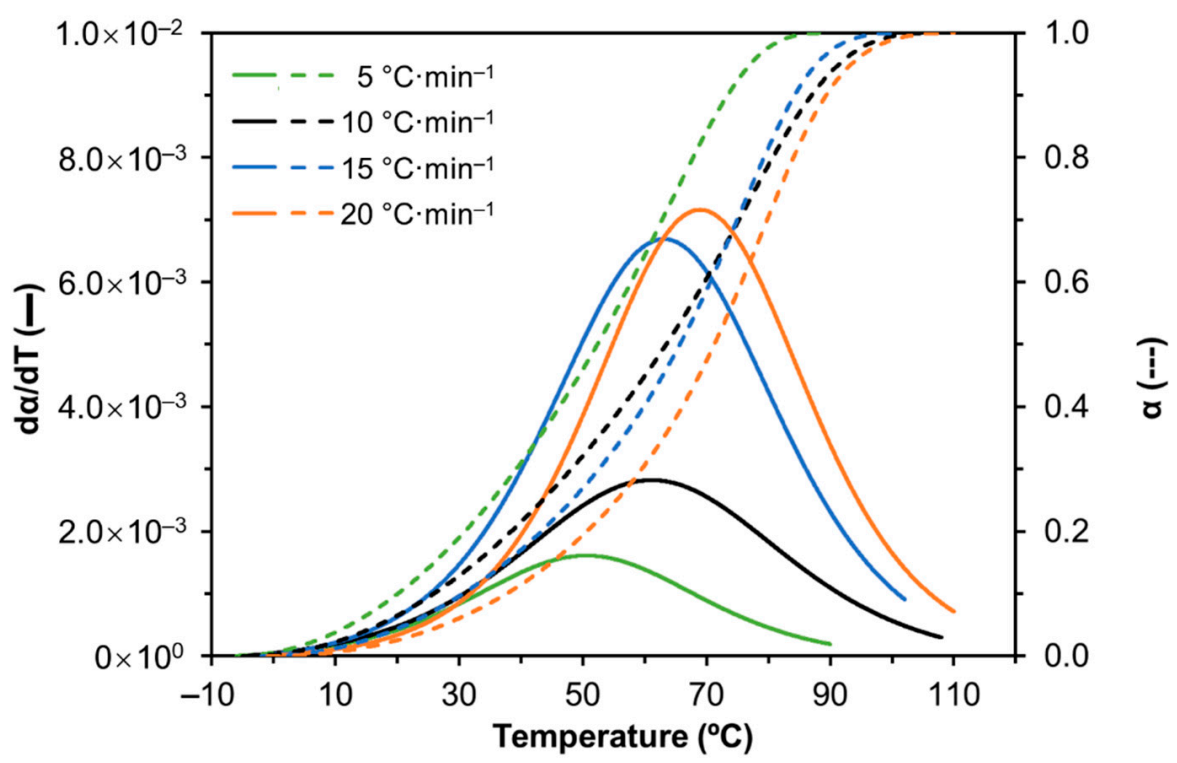

Figure 9. Effect of heating rate on the cure of LS-based PU containing $150 \mu \mathrm{L} \mathrm{PEG}_{200}$ (formulation 8, Table 1).

Next, the $E_{\mathrm{a}}$ of the curing process of LS-based PU containing PEG $200(150 \mu \mathrm{L})$ was determined using the Kissinger and the Ozawa methods, and the corresponding plots are depicted in Figure 10. From the slopes of each linear plot, $E_{\mathrm{a}}$ was 65.2 and $70.7 \mathrm{~kJ} \cdot \mathrm{mol}^{-1}$, for the Kissinger and Ozawa methods, respectively. The value of $E_{\mathrm{a}}$ for the Ozawa method is higher than the one for the Kissinger method due to approximations performed in the Ozawa method, which is in agreement with the literature data $[13,71]$.

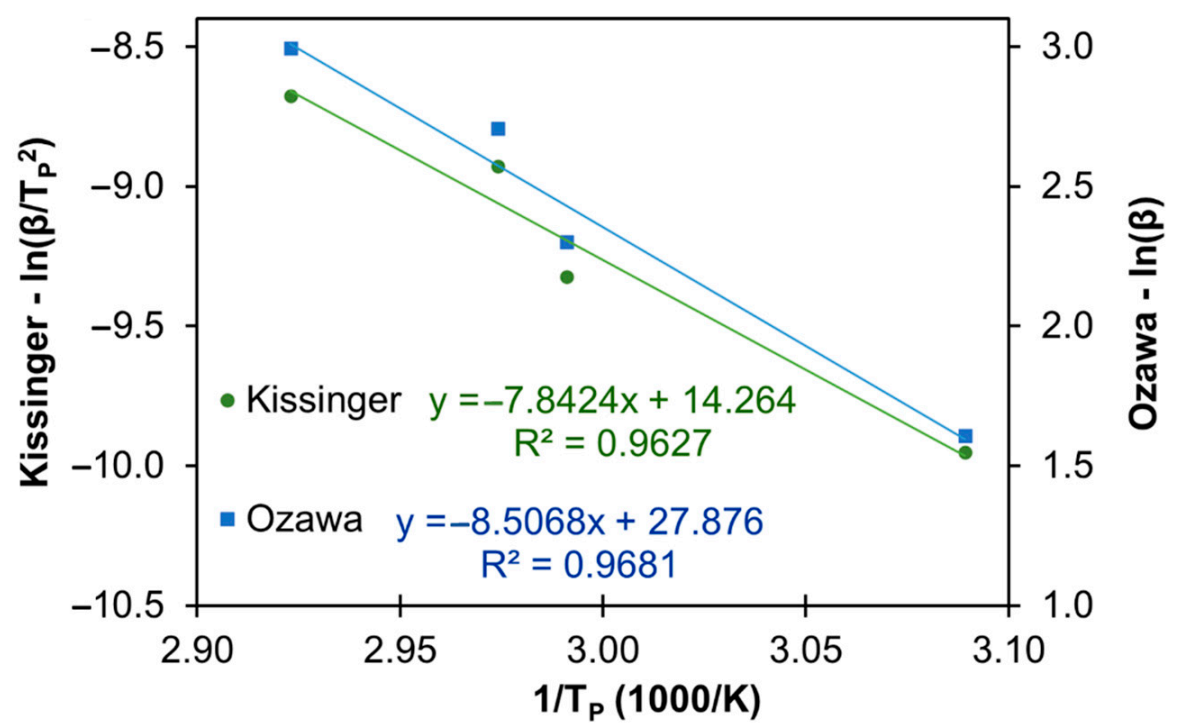

Figure 10. Kissinger and Ozawa plots for the determination of the $E_{\mathrm{a}}$ of the curing process of LS-based PU containing $150 \mu \mathrm{L} \mathrm{PEG}_{200}$ (formulation 8, Table 1). 
Since $E_{\mathrm{a}}$ is not constant and varies with $\alpha$, the Kissinger and the Ozawa methods can be used to determine the $E_{\mathrm{a}}$ throughout the entire cure reaction [13,69-71]. Therefore, the resulting Kissinger and Ozawa plots are presented in Figure 11 including the respective equations for the different $\alpha$, which are listed in Table 3. The $E_{\mathrm{a}}$ values calculated for different extends of reaction using the Kissinger and the Ozawa methods are shown in Figure 12. The trend observed is in agreement with that registered in a previous study regarding the variation of $E_{\mathrm{a}}$ throughout the curing process of a castor oil-based PU [13]. As suggested in that study, the increase in $E_{\mathrm{a}}$ at lower $\alpha$ values (from $\alpha=0.1$ to 0.7 ) can be attributed to the crosslinking within the PU network while the slight decrease in $E_{\mathrm{a}}$ at higher $\alpha$ values can be attributed to the breaking of crosslinks resulting in increasing chain flexibility. This type of behavior was also observed for epoxy resins [71].

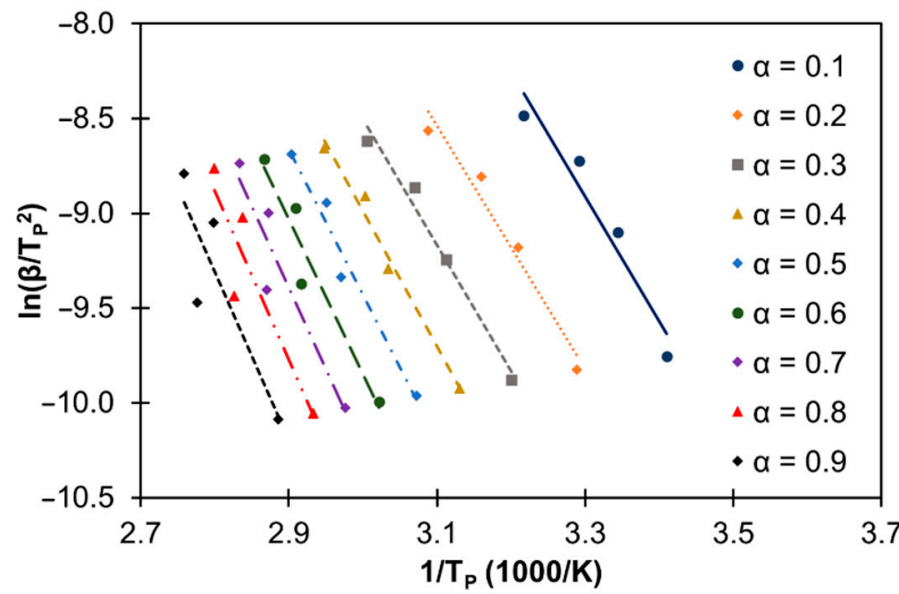

(a)

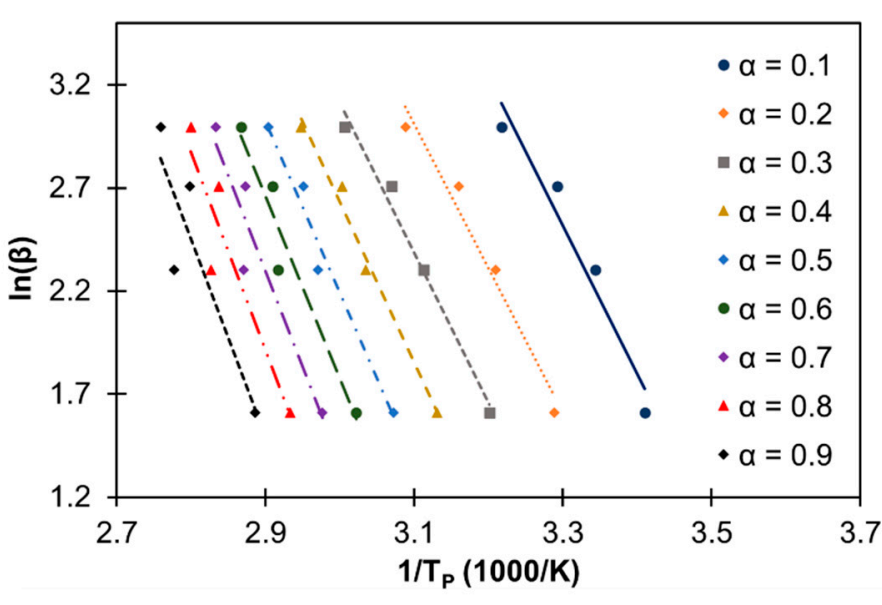

(b)

Figure 11. Determination of Ea using the Kissinger (a) and the Ozawa (b) methods for the curing process of LS-based PU containing $\mathrm{PEG}_{200}(150 \mu \mathrm{L})$.

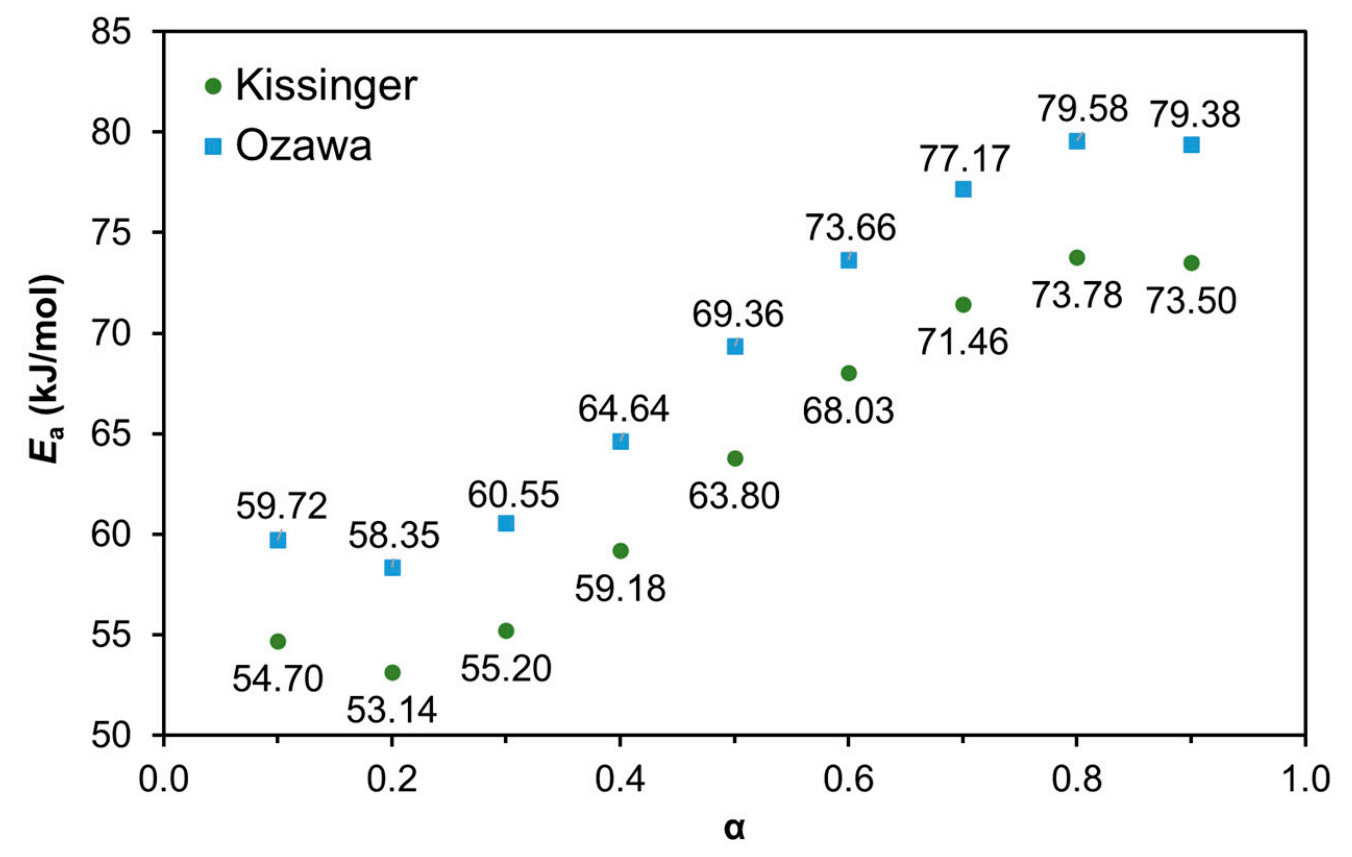

Figure 12. Plots representing the dependence of $E_{\mathrm{a}}$ with $\alpha$ using the Kissinger and the Ozawa methods. 
Table 3. Kissinger and Ozawa equations from plots in Figure 11.

\begin{tabular}{|c|c|c|c|c|}
\hline \multirow{2}{*}{$\alpha$} & \multicolumn{2}{|c|}{ Kissinger } & \multicolumn{2}{|c|}{ Ozawa } \\
\hline & Equation & $\mathbf{R}^{2}$ & Equation & $\mathbf{R}^{2}$ \\
\hline 0.1 & $y=-6.582 x+12.811$ & 0.940 & $y=-7.186 x+26.232$ & 0.950 \\
\hline 0.2 & $y=-6.395 x+11.283$ & 0.962 & $y=-7.022 x+24.780$ & 0.969 \\
\hline 0.3 & $y=-6.643 x+11.424$ & 0.980 & $y=-7.287 x+24.974$ & 0.983 \\
\hline 0.4 & $y=-7.122 x+12.378$ & 0.983 & $y=-7.779 x+25.968$ & 0.986 \\
\hline 0.5 & $y=-7.677 x+13.604$ & 0.967 & $y=-8.346 x+27.228$ & 0.972 \\
\hline 0.6 & $y=-8.186 x+14.712$ & 0.934 & $y=-8.864 x+28.365$ & 0.943 \\
\hline 0.7 & $y=-8.599 x+15.545$ & 0.889 & $y=-9.286 x+29.224$ & 0.903 \\
\hline 0.8 & $y=-8.879 x+15.979$ & 0.839 & $y=-9.576 x+29.686$ & 0.858 \\
\hline 0.9 & $y=-8.845 x+15.459$ & 0.773 & $y=-9.552 x+29.197$ & 0.799 \\
\hline
\end{tabular}

\section{Conclusions}

The results of this study demonstrate the possibility of using hardwood lignosulphonates as macropolyols in polyurethane formulations suitable for adhesive purposes. Due to some limitations in the accessibility/reactivity of hydroxyl groups in lignosulfonate (LS) in the reaction with $4^{\prime}$-methylene diphenyl diisocyanate (pMDI) and difficulties in effective homogenization of the reaction mixture, the addition of polyethylene glycol diol of low molecular weight $\left(M_{\mathrm{w}} 200, \mathrm{PEG}_{200}\right)$ seems to be advantageous to overcome, at least partially, these drawbacks. The important role of $\mathrm{PEG}_{200}$ in the consolidation of LS-based PU network via crosslinking reactions with pMDI has been demonstrated. It was also suggested that the addition of $\mathrm{PEG}_{200}$ in the LS-pMDI reaction mixture favored the interfacial interaction between the LS-based PU adhesive and the glued material (wood strips). The adhesion strength of LS-based PU was comparable to the commercial white glue. The curing kinetics of LS-based PU adhesive with addition of $\mathrm{PEG}_{200}$ showed similar trend to those observed previously with other PU formulations. The activation energy determined is within the range of $60-70 \mathrm{~kJ} \cdot \mathrm{mol}^{-1}$ depending the applied methodology. The next step would be to study the use of unrefined spent liquor for the same purpose.

Supplementary Materials: The following are available online at https:/ /www.mdpi.com/article/10 .3390/ma14227072/s1, Figure S1: TGA curve of PEG200, under inert $\mathrm{N}_{2}$ gas flow.

Author Contributions: Conceptualization, D.V.E. and A.B.-T.; methodology, D.V.E., A.B.-T., S.M. and N.G.; investigation, S.M., N.G. and L.C.; writing—original draft preparation, S.M.; writing-review and editing, D.V.E., A.B.-T., S.M., N.G. and L.C.; supervision, D.V.E. and A.B.-T. All authors have read and agreed to the published version of the manuscript.

Funding: This work was developed within the scope of the project CICECO-Aveiro Institute of Materials, UIDB/50011/2020 \& UIDP/50011/2020, financed by national funds through the Portuguese Foundation for Science and Technology (FCT)/Ministry of Science, Technology and Higher Education (MCTES), base Funding-UIDB/00511/2020 of the Laboratory for Process Engineering, Environment, Biotechnology and Energy — LEPABE—funded by national funds through the FCT /MCTES (PIDDAC) and funded by FCT and the European Social Fund (ESF) within the framework of PORTUGAL2020, namely through the Programa Operacional Regional do Centro (Centro 2020) (PhD grant $\mathrm{SFRH} / \mathrm{BD} / 121275 / 2016)$.

Institutional Review Board Statement: Not applicable.

Informed Consent Statement: Not applicable.

Data Availability Statement: Data sharing not applicable.

Acknowledgments: S.M. acknowledges Margarida Almeida at the Department of Wood Engineering, Polytechnic Institute of Viseu, for technical support (ABES testing).

Conflicts of Interest: The authors declare no conflict of interest. 


\section{References}

1. Lehmann, W.F. Wood-based composites and laminates. In Kirk-Othmer Encyclopedia of Chemical Technology; John Wiley \& Sons Inc.: New York, NY, USA, 2011; pp. 1-47.

2. Stark, N.M.; Ai, Z.; Carll, C. Wood-based composite materials. In Wood Handbook: Wood as an Engineering Material; General Technical Report, FPL-GTR-190; Ross, R.J., Ed.; U.S. Department of Agriculture, Forest Service, Forest Products Laboratory: Madison, WI, USA, 2010; pp. 11.1-11.28.

3. Frihart, C.R.; Hunt, C.G. Adhesives with wood materials. In Wood Handbook: Wood as an Engineering Material; General Technical Report FPL-GTR-190; Ross, R.J., Ed.; U.S. Department of Agriculture, Forest Service, Forest Products Laboratory: Madison, WI, USA, 2010; pp. 10.1-10.24.

4. Ormondroyd, G.A. Adhesives for wood composites. In Wood Composites (Woodhead Publishing Series in Composites Science and Engineering); Elsevier Ltd.: Waltham, MA, USA, 2015; pp. 47-66, ISBN 9781782424772.

5. Lithner, D.; Larsson, A.; Dave, G. Environmental and health hazard ranking and assessment of plastic polymers based on chemical composition. Sci. Total Environ. 2011, 409, 3309-3324. [CrossRef]

6. Pizzi, A. Natural adhesives, binders and matrices for wood and fiber composites: Chemistry and technology. In Lignocellulosic Fibers and Wood Handbook: Renewable Materials for Today's Environment; Belgacem, N., Pizzi, A., Eds.; Scrivener Publishing LLC.: Hoboken, NJ, USA, 2016; pp. 277-303.

7. Roffael, E. Volatile organic compounds and formaldehyde in nature, wood and wood based panels. Holz als Roh Werkst. 2006, 64, 144-149. [CrossRef]

8. Engels, H.-W.; Pirkl, H.-G.; Albers, R.; Albach, R.W.; Krause, J.; Hoffmann, A.; Casselmann, H.; Dormish, J. Polyurethanes: Versatile Materials and Sustainable Problem Solvers for Today's Challenges. Angew. Chem. Int. Ed. 2013, 52, 9422-9441. [CrossRef]

9. Fink, J.K. Reactive Polymers: Fundamentals and Applications: A Concise Guide to Industrial Polymers; Elsevier Inc.: Waltham, MA, USA, 2018; pp. 71-138, ISBN 9780128145098.

10. Janik, H.; Sienkiewicz, M.; Kucinska-lipka, J. Polyurethanes. In Handbook of Thermoset Plastics; Dodiuk, H., Goodman, S.H., Eds.; Elsevier Inc.: Waltham, MA, USA, 2014; pp. 253-295, ISBN 9781455731077.

11. Gama, N.V.; Ferreira, A.; Barros-Timmons, A. Polyurethane Foams: Past, Present, and Future. Materials 2018, 11, 1841. [CrossRef]

12. Grand View Research. Polyurethane Market Size, Share \& Trends Analysis Report—Sample Report. Available online: https: // www.grandviewresearch.com/industry-analysis/polyurethane-pu-market\# (accessed on 7 October 2021).

13. Gama, N.; Ferreira, A.; Timmons, A.B. Cure and performance of castor oil polyurethane adhesive. Int. J. Adhes. Adhes. 2019, 95, 102413. [CrossRef]

14. Bresolin, D.; Valerio, A.; Oliveira, D.; Lenzi, M.K.; Sayer, C.; De Araújo, P.H.H. Polyurethane Foams Based on Biopolyols from Castor Oil and Glycerol. J. Polym. Environ. 2017, 26, 2467-2475. [CrossRef]

15. Carriço, C.S.; Fraga, T.; Pasa, V.M. Production and characterization of polyurethane foams from a simple mixture of castor oil, crude glycerol and untreated lignin as bio-based polyols. Eur. Polym. J. 2016, 85, 53-61. [CrossRef]

16. Cinelli, P.; Anguillesi, I.; Lazzeri, A. Green synthesis of flexible polyurethane foams from liquefied lignin. Eur. Polym. J. 2013, 49, 1174-1184. [CrossRef]

17. Tavares, L.B.; Boas, C.R.S.V.; Schleder, G.; Nacas, A.; Rosa, D.D.S.; Santos, L.T. Bio-based polyurethane prepared from Kraft lignin and modified castor oil. Express Polym. Lett. 2016, 10, 927-940. [CrossRef]

18. Cassales, A.; Ramos, L.A.; Frollini, E. Synthesis of bio-based polyurethanes from Kraft lignin and castor oil with simultaneous film formation. Int. J. Biol. Macromol. 2019, 145, 28-41. [CrossRef] [PubMed]

19. Zhang, W.; Zhang, Y.; Liang, H.; Liang, D.; Cao, H.; Liu, C.; Qian, Y.; Lu, Q.; Zhang, C. High bio-content castor oil based waterborne polyurethane/sodium lignosulfonate composites for environmental friendly UV absorption application. Ind. Crop. Prod. 2019, 142, 111836. [CrossRef]

20. Ekkaphan, P.; Sooksai, S.; Chantarasiri, N.; Petsom, A. Bio-Based Polyols from Seed Oils for Water-Blown Rigid Polyurethane Foam Preparation. Int. J. Polym. Sci. 2016, 2016, 1-11. [CrossRef]

21. Stirna, U.; Fridrihsone, A.; Lazdina, B.; Misane, M.; Vilsone, D. Biobased Polyurethanes from Rapeseed Oil Polyols: Structure, Mechanical and Thermal Properties. J. Polym. Environ. 2012, 21, 952-962. [CrossRef]

22. Mizera, K.; Ryszkowska, J. Thermal properties of polyurethane elastomers from soybean oil-based polyol with a different isocyanate index. J. Elastomers Plast. 2018, 51, 157-174. [CrossRef]

23. Gama, N.V.; Soares, B.; Freire, C.; Silva, R.; Ferreira, A.; Barros-Timmons, A. Effect of unrefined crude glycerol composition on the properties of polyurethane foams. J. Cell. Plast. 2017, 54, 633-649. [CrossRef]

24. Alinejad, M.; Henry, C.; Nikafshar, S.; Gondaliya, A.; Bagheri, S.; Chen, N.; Singh, S.K.; Hodge, D.B.; Nejad, M. Lignin-Based Polyurethanes: Opportunities for Bio-Based Foams, Elastomers, Coatings and Adhesives. Polymers 2019, 11, 1202. [CrossRef]

25. Luo, S.; Gao, L.; Guo, W. Effect of incorporation of lignin as bio-polyol on the performance of rigid lightweight wood-polyurethane composite foams. J. Wood Sci. 2020, 66. [CrossRef]

26. Gouveia, J.; Da Costa, C.L.; Tavares, L.B.; Dos Santos, D.J. Synthesis of Lignin-Based Polyurethanes: A Mini-Review. Mini-Rev. Org. Chem. 2019, 16, 345-352. [CrossRef]

27. Zhang, Q.; Zhang, G.; Xu, J.; Gao, C.; Wu, Y. Recent advances on lignin-derived polyurethane polymers. Rev. Adv. Mater. Sci. 2015, 40, 146-154. 
28. Xu, C.; Ferdosian, F. Lignin-Based Polyurethane (PU) resins and foams. In Conversion of Lignin into Bio-Based Chemicals and Materials; Springer: Berlin/Heidelberg, Germany, 2017; pp. 133-156, ISBN 9783662549599.

29. Li, H.; Liang, Y.; Li, P.; He, C. Conversion of biomass lignin to high-value polyurethane: A review. J. Bioresour. Bioprod. 2020, 5, 163-179. [CrossRef]

30. De Oliveira, F.; Ramires, E.C.; Frollini, E.; Belgacem, M.N. Lignopolyurethanic materials based on oxypropylated sodium lignosulfonate and castor oil blends. Ind. Crop. Prod. 2015, 72, 77-86. [CrossRef]

31. Kazzaz, A.E.; Feizi, Z.H.; Fatehi, P. Grafting strategies for hydroxy groups of lignin for producing materials. Green Chem. 2019, 21, 5714-5752. [CrossRef]

32. Cateto, C.A.; Barreiro, M.F.; Ottati, C.; Lopretti, M.; Rodrigues, A.E.; Belgacem, M.N. Lignin-based rigid polyurethane foams with improved biodegradation. J. Cell. Plast. 2013, 50, 81-95. [CrossRef]

33. Cateto, C.; Barreiro, M.; Rodrigues, A. Monitoring of lignin-based polyurethane synthesis by FTIR-ATR. Ind. Crop. Prod. 2008, 27, 168-174. [CrossRef]

34. Evtuguin, D.; Andreolety, J.; Gandini, A. Polyurethanes based on oxygen-organosolv lignin. Eur. Polym. J. 1998, 34, 1163-1169. [CrossRef]

35. Gandini, A.; Belgacem, M.N.; Guo, Z.X.; Montanari, S. Lignins as macromonomers for polyesters and polyurethanes. In Chemical Modification, Properties, and Usage of Lignin; Hu, T.Q., Ed.; Springer Science \& Business Media: New York, NY, USA, 2002; pp. 57-80, ISBN 9781461351733.

36. Hatakeyama, H. Polyurethanes containing lignin. In Chemical Modification, Properties, and Usage of Lignin; Hu, T.Q., Ed.; Springer Science \& Business Media: New York, NY, USA, 2002; pp. 41-56, ISBN 978-1-4613-5173-3.

37. Llovera, L.; Benjelloun-Mlayah, B.; Delmas, M. Organic Acid Lignin-based Polyurethane Films: Synthesis Parameter Optimization. BioResources 2016, 11. [CrossRef]

38. Zhang, Y.; Liao, J.; Fang, X.; Bai, F.; Qiao, K.; Wang, L. Renewable High-Performance Polyurethane Bioplastics Derived from Lignin-Poly(E-caprolactone). ACS Sustain. Chem. Eng. 2017, 5, 4276-4284. [CrossRef]

39. Lang, J.M.; Shrestha, U.M.; Dadmun, M. The Effect of Plant Source on the Properties of Lignin-Based Polyurethanes. Front. Energy Res. 2018, 6. [CrossRef]

40. Griffini, G.; Passoni, V.; Suriano, R.; Levi, M.; Turri, S. Polyurethane Coatings Based on Chemically Unmodified Fractionated Lignin. ACS Sustain. Chem. Eng. 2015, 3, 1145-1154. [CrossRef]

41. Nacas, A.M.; Ito, N.M.; de Sousa, R.R., Jr.; Spinacé, M.A.; Dos Santos, D.J. Effects of NCO:OH ratio on the mechanical properties and chemical structure of Kraft lignin-based polyurethane adhesive. J. Adhes. 2016, 93, 18-29. [CrossRef]

42. Kissinger, H.E. Reaction Kinetics in Differential Thermal Analysis. Anal. Chem. 1957, 29, 1702-1706. [CrossRef]

43. Ozawa, T. A New Method of Analyzing Thermogravimetric Data. Bull. Chem. Soc. Jpn. 1965, 38, 1881-1886. [CrossRef]

44. Zhang, X. Applications of Kinetic Methods in Thermal Analysis: A Review. Eng. Sci. 2020, 14, 1-13. [CrossRef]

45. Marques, A.P.; Evtuguin, D.; Magina, S.; Amado, F.; Prates, A. Chemical Composition of Spent Liquors from Acidic MagnesiumBased Sulphite Pulping ofEucalyptus globulus. J. Wood Chem. Technol. 2009, 29, 322-336. [CrossRef]

46. Fatehi, P.; Ni, Y. Integrated forest biorefinery-Sulfite process. In Sustainable Production of Fuels, Chemicals, and Fibers from Forest Biomass (ACS Symposium Series); Zhu, J., Zhang, X., Pan, X., Eds.; American Chemical Society: Washington, DC, USA, 2011; Volume 1067, pp. 409-441, ISBN 9780841226432.

47. Pereira, S.; Portugal-Nunes, D.J.; Evtuguin, D.; Serafim, L.; Xavier, A.M. Advances in ethanol production from hardwood spent sulphite liquors. Process. Biochem. 2013, 48, 272-282. [CrossRef]

48. Magina, S.; Barros-Timmons, A.; Evtuguin, D.V. Changes in potentialities of acidic sulphite pulping spent liquors while reprofiling mill from paper-grade to dissolving pulps. In Proceedings of the 15th European Workshop on Lignocellulosics and Pulp (EWLP2018)—Posters Presentations, Aveiro, Portugal, 26-29 June 2018; pp. 303-306.

49. Gautam, R.; Vanga, S.; Ariese, F.; Umapathy, S. Review of multidimensional data processing approaches for Raman and infrared spectroscopy. EPJ Tech. Instrum. 2015, 2, 8. [CrossRef]

50. Royall, P.G.; Huang, C.-Y.; Tang, S.-W.J.; Duncan, J.; Van-De-Velde, G.; Brown, M. The development of DMA for the detection of amorphous content in pharmaceutical powdered materials. Int. J. Pharm. 2005, 301, 181-191. [CrossRef] [PubMed]

51. Gmelin, E.; Sarge, S.M. Calibration of differential scanning calorimeters. Pure Appl. Chem. 1995, 67, 1789-1800. [CrossRef]

52. Martins, J.A.; Cruz-Pinto, J.J.C. The temperature calibration on cooling of differential scanning calorimeters. Thermochim. Acta 1999, 332, 179-188. [CrossRef]

53. Boerjan, W.; Ralph, J.; Baucher, M. Lignin Biosynthesis. Annu. Rev. Plant Biol. 2003, 54, 519-546. [CrossRef]

54. Calvo-Flores, F.G. Lignin: A Renewable Raw Material. Encycl. Renew. Sustain. Mater. 2020, 1-20. [CrossRef]

55. Agarwal, U.P.; Atalla, R.H. Vibrational spectroscopy. In Lignin and Lignans: Advances in Chemistry; Heitner, C., Dimmel, D., Schmidt, J.A., Eds.; Taylor and Francis Group, LLC.: Boca Raton, FL, USA, 2010; pp. 103-136, ISBN 9781574444865.

56. Hergert, H.L. Infrared spectra. In Lignins: Occurrence, Formation, Structure and Reactions; Sarkanen, K.V., Ludwig, C.H., Eds.; John Wiley \& Sons, Inc.: New York, NY, USA, 1971; pp. 267-297, ISBN 978-0471754220.

57. Tejado, A.; Kortaberria, G.; Peña, C.; Labidi, J.; Echeverria, J.; Mondragon, I. Isocyanate curing of novolac-type ligno-phenolformaldehyde resins. Ind. Crop. Prod. 2008, 27, 208-213. [CrossRef]

58. Bellamy, L.J. The infrared spectra of complex molecules. In Advances in Infrared Group Frequencies, 2nd ed.; Chapmanand Hall: London, UK; New York, NY, USA, 1980; Volume 2, ISBN 978-94-011-6522-8. 
59. Jakab, E.; Faix, O.; Till, F.; Székely, T. Thermogravimetry/Mass Spectrometry of Various Lignosulfonates as well as of a Kraft and Acetosolv Lignin. Holzforschung 1991, 45, 355-360. [CrossRef]

60. Brebu, M.; Vasile, C. Thermal degradation of lignin-A review. Cellul. Chem. Technol. 2010, 44, 353-363.

61. Zou, J.; Chen, Y.; Liang, M.; Zou, H. Effect of hard segments on the thermal and mechanical properties of water blown semi-rigid polyurethane foams. J. Polym. Res. 2015, 22, 120. [CrossRef]

62. Menard, K. Dynamic Mechanical Analysis: A Practical Introduction, 2nd ed.; CRC Press, Taylor \& Francis Group, LLC.: Boca Raton, FL, USA, 2008; ISBN 9781420053128.

63. Sundararajan, S.; Kumar, A.; Chakraborty, B.C.; Samui, A.B.; Kulkarni, P.S. Poly(ethylene glycol) (PEG)-modified epoxy phasechange polymer with dual properties of thermal storage and vibration damping. Sustain. Energy Fuels 2018, 2, 688-697. [CrossRef]

64. Boonlert-Uthai, T.; Samthong, C.; Somwangthanaroj, A. Synthesis, Thermal Properties and Curing Kinetics of Hyperbranched BPA/PEG Epoxy Resin. Polymers 2019, 11, 1545. [CrossRef] [PubMed]

65. Yoshida, H.; Mörck, R.; Kringstad, K.P.; Hatakeyama, H. Kraft lignin in polyurethanes. II. Effects of the molecular weight of kraft lignin on the properties of polyurethanes from a kraft lignin-polyether triol-polymeric MDI system. J. Appl. Polym. Sci. 1990, 40, 1819-1832. [CrossRef]

66. Hunt, C.; Frihart, C.R.; Dunky, M.; Rohumaa, A. Understanding Wood Bonds-Going Beyond What Meets the Eye: A Critical Review. Rev. Adhes. Adhes. 2018, 6, 369-440. [CrossRef]

67. Thring, R.W.; Ni, P.; Aharoni, S.M. Molecular weight effects of the soft segment on the ultimate properties of lignin-derived polyurethanes. Int. J. Polym. Mater. 2004, 53, 507-524. [CrossRef]

68. Frihart, C.R.; Lorenz, L. Standard Test Method ASTM D 7998-19 for the Cohesive Strength Development of Wood Adhesives. J. Vis. Exp. 2020, e61184. [CrossRef] [PubMed]

69. Sahoo, S.; Kalita, H.; Mohanty, S.; Nayak, S.K. Meticulous study on curing kinetics of green polyurethane-clay nanocomposite adhesive derived from plant oil: Evaluation of decomposition activation energy using TGA analysis. J. Macromol. Sci. Part A 2017, 54, 819-826. [CrossRef]

70. Singh, A.K.; Panda, B.P.; Mohanty, S.; Nayak, S.K.; Gupta, M.K. Thermokinetics behavior of epoxy adhesive reinforced with low viscous aliphatic reactive diluent and nano-fillers. Korean J. Chem. Eng. 2017, 34, 3028-3040. [CrossRef]

71. Thanki, J.D.; Parsania, P.H. Dynamic DSC curing kinetics and thermogravimetric study of epoxy resin of 9,9'-bis(4hydroxyphenyl)anthrone-10. J. Therm. Anal. Calorim. 2017, 130, 2145-2156. [CrossRef] 